\title{
Adaptabilidade e estabilidade da característica produtividade de grãos dos grupos comerciais carioca e preto de feijão
}

\section{Adaptability and stability for the trait grain yield for the color and black commercial groups in common bean}

\author{
Vanesca Priscila Camargo Rocha'; Vânia Moda-Cirino²; Deonisio Destro ${ }^{3 *}$; \\ Nelson da Silva Fonseca Júnior ${ }^{4}$; Cássio Egídio Cavenaghi Prete ${ }^{3}$
}

\begin{abstract}
Resumo
O objetivo deste trabalho foi avaliar a estabilidade e adaptabilidade de produtividade de grãos das linhagens fixadas e cultivares de feijão do grupo comercial carioca e do grupo comercial preto, oriundas do programa de melhoramento genético do IAPAR e comparar os métodos de Wrick, Eberhart \& Russell, Cruz et al. e AMMI. Na safra das águas 2006/2007 e seca 2007 foram conduzidos três ensaios do grupo carioca e dois do grupo preto, num total de 27 ambientes no estado do Paraná. Cada ensaio foi constituído por 20 genótipos. Os genótipos indicados foram LP 0622 (G13) (carioca 1); LP 0604 (G7) (carioca 2); LP 0652 (G5), LP 0654 (G7) e LP 0665 (G18) (preto 1); e LP 0673 G9 (preto 2). Todos esses genótipos apresentaram alto potencial de produtividade de grãos com ampla adaptação e estabilidade. O ambiente mais estável e mais produtivo foi Ponta Grossa - seca para todos os grupos comerciais de feijão. Na análise de comparação entre os métodos, o método de Eberhart \& Russel e Cruz et al. apresentaram correlação positiva e significativa em $80 \%$ dos grupos avaliados para a estabilidade e adaptabilidade dos genótipos.

Palavras-chave: Phaseolus vulgares, melhoramento genético, interação genótipo x ambiente
\end{abstract}

\begin{abstract}
The objective of this study was to evaluate grain yield stability and adaptability from the fixed lines and cultivars of common bean of color and black comercial groups from IAPAR's common bean breeding program, as well as to compare the methods of Wrick, Eberhart \& Russell, Cruz et al. and AMMI. Three trials using the carioca group and two using the black group were conducted during the 2006/2007 water crop season and the 2007 dry crop season, in 27 environments in the State of Paraná. Each trial included 20 genotypes. The following genotypes were selected: LP 0622 (G13) (carioca 1), LP 0604 (G7) (carioca 2), LP 0652 (G5), LP 0654 (G7) e LP 0665 (G18) (preto 1) e LP 06 73G9 (preto 2). All genotypes showed high grain yield potential with wide adaptability and stability. The environment more stable and more productive was Ponta Grossa - dry season for the all studied groups. As for the method comparisons, the Eberhart \& Russell and Cruz et al. showed significant and positive correlation in $80 \%$ of the studied groups for genotypes stability and adaptability.

Key words: Phaseolus vulgares, breeding, genotype $\mathrm{x}$ environment interaction, cultivars recommendation.

\footnotetext{
1 Mestranda em Agronomia da Universidade Estadual de Londrina (UEL), Londrina - PR. E-mail: vanescaagro@bol.com.br

2 Pesquisadora do Instituto Agronômico do Paraná (IAPAR), Área de Melhoramento e Genética Vegetal. E-mail: vamoci@iapar.br

${ }_{3}$ Professor da Universidade Estadual de Londrina / Departamento de Agronomia. E-mail: deonisiodestro@yahoo.com; cassio@, uel.br

${ }^{4}$ Pesquisador do Instituto Agronômico do Paraná (IAPAR), Área de Melhoramento e Genética Vegetal. E-mail: nsfjr587@yahoo. com.br

* Autor para correspondência.
} 


\section{Introdução}

O feijão (Phaseolus vulgares L.) é um alimento básico da população brasileira e uma das mais importantes fontes de proteína na alimentação humana, principalmente, para a população de baixo poder aquisitivo. Nos últimos anos, o Brasil tem se destacado no cenário agrícola internacional como um dos maiores produtores e consumidores desta leguminosa. Na safra 2006/2007 a produção nacional anual de feijão chegou a 3,339.7 toneladas de grãos em uma área cultivada de 4,087.8 hectares (CONAB 2007). A cultura do feijão pode ser altamente influenciada pelas condições ambientais, fazendo com que os fatores adversos causem a diminuição da produção.

Portanto, essa é uma questão que o melhorista vem enfrentando para conseguir cultivares que se adaptem às variações ambientais. O comportamento diferenciado dos genótipos é devido às diferenças de ambientes. Porém, sabe-se que um fenótipo é função do genótipo, do ambiente e também da interação genótipo $\mathrm{x}$ ambiente (GxA).

Para Cruz e Regazzi (1997), a interação entre genótipos e ambientes, está associada a dois fatores: o primeiro denominado simples é proporcionado pela diferença entre genótipos; o segundo denominado complexo é dado pela ausência de correlação entre os genótipos.

A adaptabilidade é a capacidade dos genótipos aproveitarem vantajosamente o estímulo do ambiente; a estabilidade é a capacidade dos genótipos mostrarem um comportamento altamente previsível em função do estímulo do ambiente e uma das alternativas propostas para amenizar a influência dessa interação é a recomendação de cultivares com ampla adaptabilidade e boa estabilidade (CRUZ; CARNEIRO, 2003).

Uma das etapas finais do melhoramento vegetal é a verificação da interação genótipo por ambiente e para isso existem vários métodos para a avaliação da adaptabilidade e estabilidade dos genótipos nos diferentes ambientes. As metodologias mais utilizadas são as baseadas em análises de regressão linear simples, cujo exemplo clássico é o modelo matemático estabelecido por (EBERHART; RUSSELL, 1966). Essa metodologia utiliza a regressão linear que está baseada no índice ambiental e este índice é a variável independente. A produtividade média de grãos, de cada cultivar, em cada ambiente, é a variável dependente (EBERHART; RUSSELL, 1966).

Um outro método também bastante utilizado é o método da ecovalência (Wricke, 1965), onde se estima apenas a estabilidade dos genótipos, decompondo a soma de quadrados da interação nas partes correspondentes à participação de cada genótipo nesta interação.

O método proposto por Cruz et al. (1989), utiliza a regressão linear da média de cada genótipo em relação a um índice ambiental. Neste método a reta de regressão possui dois segmentos, um para os ambientes desfavoráveis e outro para os ambientes favoráveis. A inclinação dos segmentos é dada por $\beta 1$, para os ambientes desfavoráveis, e $\beta 1+\beta 2$ para os ambientes favoráveis. Esta metodologia necessita que um grande número de ambientes, para que em cada grupo de ambientes exista número suficiente de pontos para se estabelecer a regressão.

Um método mais recente que está sendo estudado para a análise de adaptabilidade e estabilidade é o modelo "additive main effects and multiplicative interaction analysis" (AMMI), que decompõem os efeitos da interação de GxA, em uma porção denominada padrão, que possibilita a identificação de fatores ambientais e genotípicos mais diretamente relacionados à interação, e numa outra porção denominada ruído (OLIVEIRA et al., 2003). Uma das vantagens que este método proporciona para a interpretação desta análise é a construção dos biplots, propiciando quais genótipos são mais adaptáveis e estáveis a determinados ambientes. A análise AMMI pode ajudar tanto para a identificação de genótipos de alta produtividade de grãos e largamente adaptados, como na realização 
do chamado zoneamento agronômico, com fins de recomendação regionalizada e de seleção de locais de teste (ZOBEL et al. 1988).

O objetivo deste trabalho foi avaliar a influência da interação GxA na produtividade de grãos de um conjunto de linhagens fixadas de feijão utilizando quatro métodos estatísticos para fins de comparação e verificar a possibilidade de algum método contribuir com alguma informação adicional.

\section{Material e métodos}

Na safra das águas 2006/2007 e seca 2007, foram estabelecidos três ensaios do grupo comercial carioca, denominados de carioca 1,2 e 3 , e dois do grupo preto, denominados de preto 1 e preto 2 , estabelecidos em 27 ambientes do estado do Paraná. Cada ensaio foi constituído por 20 tratamentos sendo 17 linhagens da geração $\mathrm{F}_{8}$ desenvolvidas pelo programa de melhoramento genético do Instituto Agronômico do Paraná (IAPAR) e três são cultivares do IAPAR usadas como testemunhas. A escolha das testemunhas baseou-se no seguinte critério: a cultivar mais produtiva, a mais adaptada e a mais semeada pelos agricultores nas respectivas localidades. Os experimentos foram estabelecidos na época de cultivo das águas (2006/2007), com semeadura de agosto a setembro, podendo se estender até outubro (Londrina, Irati, Pato Branco); e na época de cultivo da seca (2007), com semeadura em janeiro (Irati, Ponta Grossa e Pato Branco).

As parcelas foram constituídas de duas linhas de quatro metros, espaçadas de 0,50 metros, com uma densidade de 12 a 15 plantas por metro linear. Em cada ambiente, foi conduzido um experimento em blocos casualizados, com três repetições. Foi avaliada a produtividade de grãos $\left(\mathrm{kg} / \mathrm{ha}^{-1}\right)$ de todas as linhagens e cultivares, corrigidas para $13 \%$ de umidade.

Primeiramente, foram feitas as análises de variância fatorial simples (individual e conjunta) dos ambientes e dos tratamentos com a utilização do programa Genes, desenvolvido pela Universidade Federal de Viçosa. Em seguida foram realizadas as análises de estabilidade e adaptabilidade das cultivares e das linhagens em cada região, por meio dos métodos de Wricke (1965), Eberhart e Russell (1966) e Cruz et al. (1989), com o auxilio do programa Genes (CRUZ, 2001) e também a análise de AMMI (ZOBEL et al,. 1988) utilizando-se do programa denominado Estabilidade desenvolvido na Universidade Federal de Lavras ( http://www.dex. ufla.br/ danielff/softwares.htm ). As significâncias dos coeficientes de regressão $\beta 1, \beta 1+\beta 2$, desvios $\left(\mathrm{s}^{2} \mathrm{~d}\right)$ e $\mathrm{QM}$ desvio, foram avaliados pelo teste $\mathrm{F}$, a $5 \%$ e $1 \%$ de probabilidade.

\section{Resultados e discussão}

As análises de variâncias individuais para os ensaios do grupo carioca $(1,2,3)$ e preto (1 e 2) estão apresentadas na (Tabela 1). Observa-se que as médias dos ambientes para todos os ensaios foi superior a $1.000 \mathrm{Kg} / \mathrm{ha}$, exceto para os ensaios preto 1 e preto 2 cultivados em Londrina na safra das águas 2006/2007. Todos os ensaios apresentaram coeficientes de variação abaixo de $20 \%$, com exceção do carioca 1 no ambiente 2 (Irati - águas) e preto 1, no ambiente 3 (Pato Branco - águas).

As análises de variância conjunta para os ensaios do grupo carioca $(1,2,3)$ e preto (1 e 2) estão apresentadas na (Tabela 2). Para todos os grupos, os tratamentos (genótipos), os ambientes e também a interação entre genótipos e ambientes foram significativos ao nível de $1 \%$ de probabilidade. Esses resultados indicam que os genótipos avaliados diferem geneticamente para potencial de produtividade de grãos e que os mesmos apresentam resposta diferenciada aos ambientes em que foram avaliados. Portanto, necessita-se desdobrar a interação GxA, o que pode ser feito mediante o uso das análises de estabilidade e adaptabilidade, pelo fato que, os fatores edafoclimáticos são os que mais influenciam a adaptabilidade e a estabilidade dos genótipos. 
Tabela 1. Médias dos ambientes (Londrina, Irati, Ponta Grossa e Pato Branco) localizados no Paraná e seus respectivos coeficientes de variação dos grupos de feijão carioca 1, 2, 3 e preto 1 e 2, nos anos agrícolas 2006 (feijão das águas) e 2007 (feijão da seca).

\begin{tabular}{|c|c|c|c|c|c|c|c|c|c|c|}
\hline \multirow{2}{*}{$\begin{array}{l}\text { Médias dos } \\
\text { Ambientes }^{(1)}\end{array}$} & \multicolumn{2}{|c|}{ Carioca 1} & \multicolumn{2}{|c|}{ Carioca 2} & \multicolumn{2}{|c|}{ Carioca 3} & \multicolumn{2}{|c|}{ Preto 1} & \multicolumn{2}{|c|}{ Preto 2} \\
\hline & Média & $\mathrm{CV}(\%)^{(2)}$ & Média & $\mathrm{CV}(\%)$ & Média & $\mathrm{CV}(\%)$ & Média & $\mathrm{CV}(\%)$ & Média & $\mathrm{CV}(\%)$ \\
\hline $\mathrm{A} 1$ & $1.047,45$ & 10,33 & $1.524,11$ & 6,46 & $1.241,33$ & 7,53 & 999,17 & 7,27 & 917,19 & 7,07 \\
\hline A2 & $1.619,44$ & 23,71 & $1.850,43$ & 8,80 & $1.623,64$ & 7,60 & $1.606,64$ & 7,34 & $1.536,41$ & 11,91 \\
\hline A3 & $1.584,55$ & 12,73 & $1.005,98$ & 10,82 & $2.195,29$ & 6,56 & $1.601,09$ & 35,50 & $1.838,06$ & 6,55 \\
\hline A4 & $1.716,13$ & 8,75 & $1.338,17$ & 5,41 & $1.049,17$ & 10,85 & $1.448,69$ & 7,76 & $1.851,76$ & 10,80 \\
\hline A5 & $1.246,84$ & 6,39 & - & - & $1.683,15$ & 8,52 & $2.012,17$ & 7,57 & $2.091,28$ & 7,97 \\
\hline A6 & - & - & - & - & $1.532,56$ & 6,99 & $1.002,83$ & 13,1 & $1.121,66$ & 9,14 \\
\hline Média & $1.442,88$ & 14,74 & $1.429,67$ & 8,08 & $1.554,19$ & 7,87 & $1.445,1$ & 17,78 & $1.559,39$ & 9,46 \\
\hline
\end{tabular}

('): Ambientes: Londrina - águas; Irati - águas; Irati - secas; Pato Branco - águas; Pato Branco - secas; Ponta Grossa - seca; ${ }^{(2)} \mathrm{CV}(\%)=$ porcentagem do coeficiente de variação; (-): não há dados.

Tabela 2. Quadrado médio das análises de variância conjunta da produtividade total de grãos $(\mathrm{kg} / \mathrm{ha})$ das linhagens do grupo comercial carioca em três ensaios independentes (carioca 1,2,3) e também do grupo comercial preto (1 e 2), conduzidos nos ambientes do Paraná (Londrina, Irati, Pato Branco e Ponta Grossa), nos anos agrícolas 2006 (feijão das águas) e 2007 (feijão da seca).

\begin{tabular}{|c|c|c|c|c|c|c|c|c|c|c|}
\hline \multirow{2}{*}{ F.V. } & \multicolumn{2}{|c|}{ Carioca 1} & \multicolumn{2}{|c|}{ Carioca 2} & \multicolumn{2}{|c|}{ Carioca 3} & \multicolumn{2}{|c|}{ Preto 1} & \multicolumn{2}{|c|}{ Preto 2} \\
\hline & G.L.(') & Q.M. ${ }^{(2)}$ & G.L. & Q.M. & G.L. & Q.M. & G.L. & Q.M. & G.L. & Q.M. \\
\hline Genótipos (G) & 19 & $* *$ & 19 & $* *$ & 19 & $* *$ & 19 & ** & 19 & ** \\
\hline Ambientes (A) & 5 & ** & 3 & ** & 5 & ** & 5 & ** & 5 & $* *$ \\
\hline GxA & 76 & $* *$ & 57 & $* *$ & 95 & $* *$ & 95 & $* *$ & 95 & $* *$ \\
\hline Residuo & 190 & - & 152 & - & 228 & - & 228 & - & 228 & - \\
\hline Média & \multicolumn{2}{|c|}{$1.442,88$} & \multicolumn{2}{|c|}{$1.429,67$} & \multicolumn{2}{|c|}{$1.554,19$} & \multicolumn{2}{|c|}{$1.445,1$} & \multicolumn{2}{|c|}{$1.559,39$} \\
\hline CV\% & \multicolumn{2}{|c|}{14,74} & \multicolumn{2}{|c|}{8,08} & \multicolumn{2}{|c|}{7,87} & \multicolumn{2}{|c|}{17,78} & \multicolumn{2}{|c|}{9,46} \\
\hline
\end{tabular}

** significância a 1\% de probabilidade; GL=Graus de Liberdade; QM= Quadrado Médio; (-): não há dados.

Para estimar a estabilidade dos genótipos utilizouse o método de Wricke (1965). Este método avalia a estabilidade de cada genótipo nos ambientes. $\mathrm{O}$ genótipo estável é aquele que apresenta o menor índice de Wricke (\% ecovalência), é a contibuição relativa de cada genótipo na soma de quadrado da interação genótipo por ambiente na análise de variância conjunta. Esta metodologia apresenta um inconveniente, que é devido à magnitude dos desvios dos valores esperados frente aos observados, o genótipo mais produtivo normalmente apresenta os maiores desvios, sendo normalmente, os de menor adaptabilidade por essa metodologia.

Quanto maior a produtividade de grãos, maior a contribuição para a interação GxA. Verifica-se no grupo carioca 1 (Tabela 3), que os genótipos G16 e G17 apresentaram uma interação positiva, principalmente o G17, sendo que este genótipo superou a média geral das três testemunhas em $49,1 \%$ na produtividade de grãos, e chegando a $23 \%$ (Wi\%) na contribuição da interação genótipo por ambiente. Ambos os genótipos citados conseguiram obter uma produtividade de grãos superior às testemunhas (IPR Juriti, IPR Colibri e IAPAR 81). $\mathrm{Na}$ (Tabela 4) (carioca 2), os genótipos G7, G8 e G13 superaram a produtividade de grãos média das três testemunhas (IAPAR 81, IPR Juriti, IPR Saracura) em $15,8 \%, 13,2 \%$ e $13,9 \%$, respectivamente. Entre estes três genótipos, o G7 foi o mais estável, com Wi\% igual a 0,94 . 
Tabela 3. Análise de adaptabilidade e estabilidade de 20 genótipos/cultivares de feijão Carioca 1, avaliados em 5 ambientes do estado do Paraná (Londrina, Irati, Ponta Grossa e Pato Branco), nos anos agrícolas 2006 (feijão das águas) e 2007 (feijão das seca).

\begin{tabular}{|c|c|c|c|c|c|c|c|c|c|c|}
\hline \multirow{2}{*}{$\begin{array}{l}\text { Cultivar/ } \\
\text { Linhagem }\end{array}$} & \multirow[b]{2}{*}{$\mathrm{N}^{\circ}$} & \multirow{2}{*}{$\begin{array}{l}\text { Média } \\
\text { (kg/ha) }\end{array}$} & \multirow{2}{*}{$\begin{array}{l}\text { Wricke } \\
\text { Wi (\%) }\end{array}$} & \multicolumn{3}{|c|}{ Eberhart e Russel } & \multicolumn{4}{|c|}{ Cruz, Torres e Vencovsky } \\
\hline & & & & $\beta 1$ & $\mathrm{~s}^{2} \mathrm{~d}$ & $\mathrm{R}^{2}(\%)$ & $\beta 1$ & $\beta 1+\beta 2$ & QM Desvio & $\mathrm{R}^{2}(\%)$ \\
\hline IAPAR 81 & G1 & $1.259,8$ & 2,89 & $0,91^{\mathrm{NS}}$ & $27.150,47^{*}$ & 67,59 & $0,93^{\mathrm{NS}}$ & $0,25^{\mathrm{NS}}$ & $183.899,36^{*}$ & 68,64 \\
\hline IPR JURITI & G2 & $1.629,2$ & 5,15 & $1,10^{\mathrm{NS}}$ & $60.601,13^{* *}$ & 63,22 & $1,17^{\mathrm{NS}}$ & $-1,01^{\mathrm{NS}}$ & $276.452,69 * *$ & 70,14 \\
\hline & G3 & $1.573,4$ & 2,18 & 0,63 NS & $2.834,08^{\mathrm{NS}}$ & 70,35 & $0,67^{\mathrm{NS}}$ & $-0,54^{\mathrm{NS}}$ & $60.823,48^{\mathrm{NS}}$ & 77,64 \\
\hline LP 0612 & G4 & $1.403,7$ & 0,76 & $0,70^{\mathrm{NS}}$ & $-13.310,08^{\text {NS }}$ & 96,73 & $0,69^{\mathrm{NS}}$ & $1,20^{\mathrm{NS}}$ & $4.507,50^{\mathrm{NS}}$ & 98,16 \\
\hline LP 0613 & G5 & $1.367,0$ & 2,93 & $0,41 * *$ & $-8.327,63^{\mathrm{NS}}$ & 72,85 & $0,41 * *$ & $0,56^{\mathrm{NS}}$ & $30.122,89^{\mathrm{NS}}$ & 73,12 \\
\hline LP 0614 & G6 & $1.092,0$ & 13,78 & $0,77^{\mathrm{NS}}$ & $185.118,67^{* *}$ & 24,14 & $0,92^{\mathrm{NS}}$ & $-4,03 * *$ & $569.915,21^{* *}$ & 52,01 \\
\hline LP 0615 & G7 & $1.288,9$ & 4,60 & $0,3^{* *}$ & $1.661,12^{\mathrm{NS}}$ & 36,9 & $0,27 * *$ & $1,35^{\mathrm{NS}}$ & $59.567,50^{\mathrm{NS}}$ & 50,14 \\
\hline LP 0616 & G8 & $1.359,6$ & 4,00 & $1,17^{\mathrm{NS}}$ & $41.535,34^{*}$ & 72,09 & $1,14^{\mathrm{NS}}$ & $2,23^{\mathrm{NS}}$ & $238.528,74 * *$ & 73,87 \\
\hline LP 0617 & G9 & $1.490,0$ & 0,27 & $0,92^{\mathrm{NS}}$ & $-11.749,57^{\mathrm{NS}}$ & 96,45 & $0,95^{\mathrm{NS}}$ & $0,07^{\mathrm{NS}}$ & $4.533,34^{\text {NS }}$ & 98,93 \\
\hline LP 0618 & G10 & $1.341,9$ & 4,40 & $0,77^{\mathrm{NS}}$ & $45.036,35^{* *}$ & 51,46 & $0,78^{\mathrm{NS}}$ & $0,42^{\mathrm{NS}}$ & $268.779,35^{* *}$ & 51,78 \\
\hline LP 0620 & G11 & $1.480,1$ & 4,12 & $1,39^{\mathrm{NS}}$ & $30.013,68^{*}$ & 82,11 & $1,36^{\mathrm{NS}}$ & $2,49^{\mathrm{NS}}$ & $185.722,81^{*}$ & 83,63 \\
\hline LP 0621 & G12 & $1.445,8$ & 5,31 & $1,49 *$ & $38.849,88^{*}$ & 81,42 & $1,55^{*}$ & $-0,48^{\mathrm{NS}}$ & $187.035,46^{*}$ & 85,68 \\
\hline LP 0622 & G13 & $1.510,2$ & 3,76 & $1,55^{*}$ & $8.133,04^{\mathrm{NS}}$ & 91,75 & $1,56^{*}$ & $1,29^{\mathrm{NS}}$ & $103.509,85$ NS & 91,83 \\
\hline LP 0624 & G14 & $1.320,3$ & 0,82 & $0,98^{\mathrm{NS}}$ & $-2.888,70^{\mathrm{NS}}$ & 89,47 & $1,00^{\mathrm{NS}}$ & $0,63^{\mathrm{NS}}$ & $53.107,70^{\mathrm{NS}}$ & 89,81 \\
\hline LP 0625 & G15 & $1.612,6$ & 10,76 & $1,74 * *$ & $86.842,18^{* *}$ & 76,07 & $1,60 * *$ & $6,33 * *$ & $156.445,91 *$ & 91,84 \\
\hline LP 0626 & G16 & $1.723,2$ & 3,94 & $0,65^{\mathrm{NS}}$ & $30.869,86^{*}$ & 49,84 & $0,68^{\mathrm{NS}}$ & $-0,08^{\mathrm{NS}}$ & $199.134,81^{*}$ & 51,70 \\
\hline LP 0627 & G17 & $2.217,6$ & 23,09 & $2,49 * *$ & $91.002,66^{* *}$ & 86,24 & $2,39 * *$ & $5,93 * *$ & $307.562,86^{* *}$ & 91,14 \\
\hline LP 0648 & G18 & $1.276,5$ & 0,58 & $0,91^{\mathrm{NS}}$ & $-7.278,38^{\mathrm{NS}}$ & 91,96 & $0,91^{\mathrm{NS}}$ & $1,11^{\mathrm{NS}}$ & $34.604,56^{\mathrm{NS}}$ & 92,09 \\
\hline LP 0649 & G19 & $1.315,1$ & 4,45 & $0,58^{\mathrm{NS}}$ & $32.684,75^{*}$ & 43,11 & $0,51^{*}$ & $3,16^{\mathrm{NS}}$ & $119.705,27^{\mathrm{NS}}$ & 68,32 \\
\hline LP 0650 & G20 & $1.150,9$ & 2,24 & $0,51 *$ & $-7.849,81^{\mathrm{NS}}$ & 79,02 & $0,55^{*}$ & $-0,87^{\mathrm{NS}}$ & $5.387,08^{\mathrm{NS}}$ & 96,53 \\
\hline Média & & $1.442,90$ & & & & & & & & \\
\hline
\end{tabular}

Ns não significativo; ** significativo a $1 \%$ probabilidade; * significativo a $5 \%$ probabilidade.

Para o grupo carioca 3 (Tabela 5), apenas a IPR Saracura (G3) e também o genótipo G18, foram altamente produtivos em relação às outras linhagens/cultivares. A linhagem homozigota G18 apresentou maior potencial de produtividade de grãos, superando a média das três testemunhas em $6,1 \%$, com média de produtividade de grãos de $1.849,50 \mathrm{~kg} /$ ha e Wi\% de 7,04\% na contribuição da interação GxA. A cultivar IAPAR 81, utilizada como testemunha, apresentou a maior estabilidade com $\mathrm{Wi} \%$ de $0,95 \%$.
Para o grupo preto 1 (Tabela 6), os genótipos G5, G7 e G18 destacaram-se por superar a média de produtividade de grãos das três testemunhas em $23,4 \%, 17,3 \%$ e $12,6 \%$, respectivamente, e apresentaram-se com média estabilidade. Para o grupo preto 2 (Tabela 7), os genótipos G8, G9 e G16 destacaram-se por superar a média de produtividade de grãos das três testemunhas em 15,5\%, 18,6\% e $26,6 \%$, respectivamente. O G16 obteve a maior produtividade de grãos, porém foi a menos estável, com $\mathrm{Wi} \%$ de 10,97 . 
Tabela 4. Análise de adaptabilidade e estabilidade de 20 genótipos/cultivares de feijão Carioca 2, avaliados em 4 ambientes do estado do Paraná (Londrina, Irati, Ponta Grossa e Pato Branco), nos anos agrícolas 2006 (feijão das águas) e 2007 (feijão das seca).

\begin{tabular}{|c|c|c|c|c|c|c|c|c|c|c|}
\hline \multirow{2}{*}{$\begin{array}{l}\text { Cultivar/ } \\
\text { Linhagem }\end{array}$} & \multirow[b]{2}{*}{$\mathrm{N}^{\circ}$} & \multirow{2}{*}{$\begin{array}{l}\text { Média } \\
(\mathrm{kg} / \mathrm{ha})\end{array}$} & \multirow{2}{*}{$\begin{array}{l}\text { Wricke } \\
\text { Wi (\%) }\end{array}$} & \multicolumn{3}{|c|}{ Eberhart e Russel } & \multicolumn{4}{|c|}{ Cruz, Torres e Vencovsky } \\
\hline & & & & $\beta 1$ & $\mathrm{~s}^{2} \mathrm{~d}$ & $\mathrm{R}^{2}(\%)$ & $\beta 1$ & $\beta 1+\beta 2$ & QM Desvio & $\mathrm{R}^{2}(\%)$ \\
\hline IAPAR 81 & G1 & $1.450,9$ & 2,46 & $0,88^{\mathrm{NS}}$ & $39.876,37 * *$ & 76,57 & $0,96^{\mathrm{NS}}$ & $0,38^{*}$ & $219.181,61 * *$ & 80,69 \\
\hline IPR JURITI & $\mathrm{G} 2$ & $1.622,2$ & 0,11 & 0,93 NS & $-3.169,09^{\mathrm{NS}}$ & 99,22 & $0,93^{\mathrm{NS}}$ & $0,94^{\mathrm{NS}}$ & $7.676,53^{\mathrm{NS}}$ & 99,22 \\
\hline SARACURA & G3 & $1.734,80$ & 2,41 & $1,30 * *$ & $24.366,97 * *$ & 91,67 & $1,34 * *$ & $1,09^{\mathrm{NS}}$ & $16.4087,09^{* *}$ & 92,10 \\
\hline LP 0601 & G4 & $1.103,90$ & 8,44 & $1,75^{* *}$ & $52.457,17 * *$ & 90,92 & $1,72 * *$ & $1,91 * *$ & $336.737,31^{* *}$ & 91,05 \\
\hline LP 0602 & G5 & $5.60,70$ & 4,04 & $1,46 * *$ & $33.307,94 * *$ & 91,33 & $1,28 *$ & $2,56 * *$ & $2.263,81^{\mathrm{NS}}$ & 99,91 \\
\hline LP 0603 & G6 & $1.136,40$ & 15,74 & $2,12 * *$ & $62.510,47 * *$ & 92,60 & $2,24 * *$ & $1,41^{\mathrm{NS}}$ & $307.880,66^{* *}$ & 94,33 \\
\hline LP 0604 & G7 & $1.813,40$ & 0,94 & $1,31 * *$ & $-4.059,84^{\mathrm{NS}}$ & 99,88 & $1,29 *$ & $1,40^{\mathrm{NS}}$ & $652,98^{\mathrm{NS}}$ & 99,97 \\
\hline LP 0605 & G8 & $1.825,70$ & 4,92 & $1,43 * *$ & $54.989,88 * *$ & 86,53 & $1,27^{*}$ & $2,36 * *$ & $193.900,87 * *$ & 92,68 \\
\hline LP 0606 & G9 & $1.489,00$ & 1,63 & $0,78 * *$ & $17.921,92 * *$ & 83,68 & $0,77^{\mathrm{NS}}$ & $0,85^{\mathrm{NS}}$ & $133.420,58^{* *}$ & 83,78 \\
\hline LP 0607 & G10 & 943,60 & 8,64 & $0,62 * *$ & $13.2991,32 * *$ & 34,09 & $0,62 * *$ & $0,57^{\mathrm{NS}}$ & $824.269,89 * *$ & 34,12 \\
\hline LP 0608 & G11 & $1.234,60$ & 5,95 & $0,64 * *$ & $84.317,95^{* *}$ & 45,97 & $0,64 * *$ & $0,61^{\mathrm{NS}}$ & $532.471,66^{* *}$ & 45,98 \\
\hline LP 0610 & G12 & $1.667,50$ & 1,55 & $1,29 * *$ & $9.193,90^{*}$ & 95,81 & $1,20^{\mathrm{NS}}$ & $1,82 * *$ & $30.007,49^{\mathrm{NS}}$ & 98,46 \\
\hline LP 0611 & G13 & $1.855,20$ & 14,36 & $1,15^{\mathrm{NS}}$ & $265.093,77 * *$ & 47,96 & $0,88^{\mathrm{NS}}$ & $2,79 * *$ & $1115.701,28^{* *}$ & 64,10 \\
\hline LP 0619 & G14 & $1.512,30$ & 3,03 & $1,36^{* *}$ & $29.790,80 * *$ & 90,93 & $1,50^{* *}$ & $0,47^{\mathrm{NS}}$ & $59.222,93 *$ & 97,39 \\
\hline LP 0631 & G15 & $1.369,50$ & 1,55 & $0,63 * *$ & $1.6315,25^{\mathrm{NS}}$ & 94,22 & $0,61 * *$ & $0,75^{\mathrm{NS}}$ & $25.069,37^{\mathrm{NS}}$ & 94,77 \\
\hline LP 0642 & G16 & $1.344,10$ & 7,18 & $0,16^{* *}$ & $1.231,54^{\mathrm{NS}}$ & 46,29 & $0,23 * *$ & $-0,26^{* *}$ & $1.190,75^{\mathrm{NS}}$ & 98,12 \\
\hline LP 0643 & G17 & $1.338,4$ & 9,42 & $0,32 * *$ & $89.318,80^{* *}$ & 17,11 & $0,44 * *$ & $-0,38^{* *}$ & $471.410,73^{* *}$ & 30,55 \\
\hline LP 0644 & G18 & $1.605,2$ & 5,5 & $0,47 * *$ & $46.982,11^{* *}$ & 44,04 & $0,65^{* *}$ & $-0,67 * *$ & $70.472,48^{*}$ & 87,22 \\
\hline LP 0646 & G19 & $1.377,7$ & 1,77 & $0,58 * *$ & $-4.207,71^{\mathrm{NS}}$ & 99,61 & $0,56^{* *}$ & $0,66^{\mathrm{NS}}$ & $17.692,17^{\mathrm{NS}}$ & 100,00 \\
\hline LP 0647 & $\mathrm{G} 20$ & $1.608,40$ & 0,34 & $0,83^{\mathrm{NS}}$ & $-3.460,89^{\mathrm{NS}}$ & 99,24 & $0,85^{\mathrm{NS}}$ & $0,73^{\mathrm{NS}}$ & $4.130,21^{\mathrm{NS}}$ & 99,47 \\
\hline Média & & $1.429,70$ & & & & & & & & \\
\hline
\end{tabular}

Ns não significativo; ** significativo a $1 \%$ probabilidade; * significativo a $5 \%$ probabilidade.

Tabela 5. Análise de adaptabilidade e estabilidade de 20 genótipos/cultivares de feijão Carioca 3, avaliados em 6 ambientes do estado do Paraná (Londrina, Irati, Ponta Grossa e Pato Branco), nos anos agrícolas 2006 (feijão das águas) e 2007 (feijão das seca).

\begin{tabular}{|c|c|c|c|c|c|c|c|c|c|c|}
\hline \multirow{2}{*}{$\begin{array}{l}\text { Cultivar/ } \\
\text { Linhagem }\end{array}$} & \multirow[b]{2}{*}{$\mathrm{N}^{\circ}$} & \multirow{2}{*}{$\begin{array}{l}\text { Média } \\
(\mathrm{kg} / \mathrm{ha})\end{array}$} & \multirow{2}{*}{$\begin{array}{l}\text { Wricke } \\
\text { Wi (\%) }\end{array}$} & \multicolumn{3}{|c|}{ Eberhart e Russel } & \multicolumn{4}{|c|}{ Cruz, Torres e Vencovsky } \\
\hline & & & & $\beta 1$ & $\mathrm{~s}^{2} \mathrm{~d}$ & $\mathrm{R}^{2}(\%)$ & $\beta 1$ & $\beta 1+\beta 2$ & QM Desvio & $\mathrm{R}^{2}(\%)$ \\
\hline IAPAR 81 & G1 & $1.458,60$ & 0,95 & $1,10^{\mathrm{NS}}$ & $2.773,35^{\mathrm{NS}}$ & 96,82 & $1,10^{\mathrm{NS}}$ & $1,09^{\mathrm{NS}}$ & $31.047,26^{\mathrm{NS}}$ & 96,82 \\
\hline IPR JURITI & $\mathrm{G} 2$ & $1.762,70$ & 4,33 & $1,10^{\mathrm{NS}}$ & $36.559,65^{* *}$ & 85,20 & $1,13^{\mathrm{NS}}$ & $1,03^{\mathrm{NS}}$ & $164.764,24 * *$ & 85,33 \\
\hline SARACURA & G3 & $2.008,10$ & 25,71 & $0,96^{\mathrm{NS}}$ & $254.134,19^{* *}$ & 41,29 & $1,27 * *$ & $0,04 * *$ & $813.727,59 * *$ & 53,91 \\
\hline LP 0623 & G4 & $1.314,90$ & 1,04 & $1,00^{\mathrm{NS}}$ & $5.531,17^{\mathrm{NS}}$ & 94,94 & $1,00^{\mathrm{NS}}$ & $1,02^{\mathrm{NS}}$ & $42.024,81^{*}$ & 94,94 \\
\hline LP 0628 & G5 & $1.566,70$ & 2,48 & $0,92^{\mathrm{NS}}$ & $18.858,19^{* *}$ & 87,51 & $0,86^{\mathrm{NS}}$ & $1,11^{\mathrm{NS}}$ & $86.243,79 * *$ & 88,71 \\
\hline LP 0629 & G6 & $1.387,70$ & 3,08 & $0,87^{\mathrm{NS}}$ & $22.729,48^{* *}$ & 84,27 & $0,71 * *$ & $1,33^{*}$ & $53.920,10^{*}$ & 92,35 \\
\hline LP 0630 & G7 & $1.355,10$ & 5,08 & $0,80^{*}$ & $38.184,16^{* *}$ & 74,30 & $0,85^{\mathrm{NS}}$ & $0,64 *$ & $166.388,11 * *$ & 75,23 \\
\hline LP 0632 & G8 & $1.638,40$ & 2,94 & $1,16^{*}$ & $19.880,12 * *$ & 91,34 & $1,30 * *$ & $0,71^{\mathrm{NS}}$ & $47.847,90^{*}$ & 95,84 \\
\hline LP 0633 & G9 & $1.619,70$ & 11,10 & $1,51^{*}$ & $55.597,76^{* *}$ & 88,11 & $1,34 * *$ & $2,03 * *$ & $171.572,60 * *$ & 91,58 \\
\hline LP 0634 & G10 & $1.379,20$ & 1,63 & $1,12^{\mathrm{NS}}$ & $8.737,93^{*}$ & 94,70 & $1,12^{\mathrm{NS}}$ & $1,11^{\mathrm{NS}}$ & $54.900,12^{*}$ & 94,70 \\
\hline LP 0635 & G11 & $1.668,60$ & 3,02 & $0,91^{\mathrm{NS}}$ & $23.763,14 * *$ & 84,91 & $0,90^{\mathrm{NS}}$ & $0,93^{\mathrm{NS}}$ & $114.838,03 * *$ & 84,94 \\
\hline LP 0636 & G12 & $1.370,20$ & 2,27 & $1,13^{\mathrm{NS}}$ & $14.455,92 * *$ & 92,84 & $0,97^{\mathrm{NS}}$ & $1,62 * *$ & $15.911,99^{\mathrm{NS}}$ & 98,54 \\
\hline LP 0637 & G13 & $1.693,30$ & 3,36 & $1,07^{\mathrm{NS}}$ & $28.094,68 * *$ & 87,10 & $0,98^{\mathrm{NS}}$ & $1,32 *$ & $114.932,96 * *$ & 88,79 \\
\hline LP 0638 & G14 & $1.540,00$ & 1,57 & $0,74 * *$ & $-2.214,10^{\mathrm{NS}}$ & 97,50 & $0,70 * *$ & $0,86^{\mathrm{NS}}$ & $7.606,36^{\mathrm{NS}}$ & 98,29 \\
\hline LP 0639 & G15 & $1.553,10$ & 1,73 & $0,71 * *$ & $-3.798,64^{\mathrm{NS}}$ & 98,82 & $0,75^{* *}$ & $0,60 *$ & $1.242,89^{\mathrm{NS}}$ & 99,69 \\
\hline LP 0640 & G16 & $1.513,70$ & 5,59 & $0,95^{\mathrm{NS}}$ & $51.034,65^{* *}$ & 76,14 & $0,84^{\mathrm{NS}}$ & $1,30^{\mathrm{NS}}$ & $192.955,68^{* *}$ & 79,45 \\
\hline LP 0641 & G17 & $1.442,90$ & 3,34 & $1,22 * *$ & $19.484,39 * *$ & 92,24 & $1,30 * *$ & $0,97^{\mathrm{NS}}$ & $81.604,48^{* *}$ & 93,53 \\
\hline LP 0645 & G18 & $1.849,50$ & 7,04 & $1,06^{\mathrm{NS}}$ & $65.304,20 * *$ & 75,94 & $0,93^{\mathrm{NS}}$ & $1,46^{* *}$ & $239.212,41 * *$ & 79,53 \\
\hline LP 0651 & G19 & $1.474,10$ & 6,38 & $0,93 * *$ & $58.543,85^{* *}$ & 72,94 & $1,20^{*}$ & $0,14 * *$ & $86.604,28^{* *}$ & 90,78 \\
\hline IPR COLIBRI & G20 & $1.487,10$ & 7,35 & $0,73 * *$ & $55.113,49 * *$ & 63,68 & $0,75^{* *}$ & $0,68^{*}$ & $239.767,66^{* *}$ & 63,78 \\
\hline Média & & $1.554,20$ & & & & & & & & \\
\hline
\end{tabular}


Tabela 6. Análise de adaptabilidade e estabilidade de 20 genótipos/cultivares de feijão Preto 1, avaliados em 6 ambientes do estado do Paraná (Londrina, Irati, Ponta Grossa e Pato Branco), nos anos agrícolas 2006 (feijão das águas) e 2007 (feijão das seca).

\begin{tabular}{|c|c|c|c|c|c|c|c|c|c|c|}
\hline \multirow{2}{*}{$\begin{array}{c}\text { Cultivar/ } \\
\text { Linhagem }\end{array}$} & \multirow[b]{2}{*}{$\mathrm{N}^{\circ}$} & \multirow{2}{*}{$\begin{array}{l}\text { Média } \\
\text { (kg/ha) }\end{array}$} & \multirow{2}{*}{$\begin{array}{l}\text { Wricke } \\
\text { Wi (\%) }\end{array}$} & \multicolumn{3}{|c|}{ Eberhart e Russel } & \multicolumn{4}{|c|}{ Cruz, Torres e Vencovsky } \\
\hline & & & & $\beta 1$ & $\mathrm{~s}^{2} \mathrm{~d}$ & $\mathrm{R}^{2}(\%)$ & $\beta 1$ & $\beta 1+\beta 2$ & QM Desvio & $\mathrm{R}^{2}(\%)$ \\
\hline $\begin{array}{l}\text { IPR } \\
\text { UIRAPURU }\end{array}$ & G1 & $1.682,40$ & 2,53 & $1,21^{\mathrm{NS}}$ & $5.248,30^{\mathrm{NS}}$ & 91,20 & $1,18^{\mathrm{NS}}$ & $1,32^{\mathrm{NS}}$ & $106.669,20^{\mathrm{NS}}$ & 91,39 \\
\hline $\begin{array}{l}\text { IPR } \\
\text { CHOPIM }\end{array}$ & G2 & $1.301,40$ & 5,45 & $0,75^{\mathrm{NS}}$ & $44.112,83^{*}$ & 62,24 & $0,77^{\mathrm{NS}}$ & $0,70^{\mathrm{NS}}$ & $263.712,09 * *$ & 62,35 \\
\hline $\begin{array}{l}\text { IPR } \\
\text { GRAUNA }\end{array}$ & G3 & $1.306,20$ & 3,62 & $0,60^{*}$ & $-685,61^{\mathrm{NS}}$ & 76,55 & $0,65^{\mathrm{NS}}$ & $0,45^{\mathrm{NS}}$ & $80.078,30^{\mathrm{NS}}$ & 77,99 \\
\hline LP 0669 & G4 & $1.193,80$ & 3,15 & $0,84^{\mathrm{NS}}$ & $18.130,79^{\mathrm{NS}}$ & 77,20 & $0,82^{\mathrm{NS}}$ & $0,93^{\mathrm{NS}}$ & $158.933,53^{\mathrm{NS}}$ & 77,44 \\
\hline LP 0652 & G5 & $1.764,80$ & 3,21 & $0,93^{\mathrm{NS}}$ & $22.955,57^{\mathrm{NS}}$ & 78,83 & $0,80^{\mathrm{NS}}$ & $1,38^{\mathrm{NS}}$ & $134.851,17^{\mathrm{NS}}$ & 84,13 \\
\hline LP 0653 & G6 & $1.362,40$ & 5,09 & $0,96^{\mathrm{NS}}$ & $50.181,36^{*}$ & 71,01 & $0,85^{\mathrm{NS}}$ & $1,34^{\mathrm{NS}}$ & $256.267,58^{* *}$ & 74,28 \\
\hline LP 0654 & G7 & $1.677,80$ & 6,64 & $1,57 * *$ & $11.237,72^{\mathrm{NS}}$ & 93,39 & $1,61 * *$ & $1,40^{\mathrm{NS}}$ & $126.929,41^{\mathrm{NS}}$ & 93,69 \\
\hline LP 0655 & G8 & $1.562,10$ & 6,99 & $0,66^{*}$ & $55.044,73 * *$ & 51,77 & $0,86^{\mathrm{NS}}$ & $-0,05 * *$ & $196.325,53^{*}$ & 69,28 \\
\hline LP 0656 & G9 & $1.492,30$ & 3,45 & $0,88^{\mathrm{NS}}$ & $24.548,46^{\mathrm{NS}}$ & 76,31 & $1,01^{\mathrm{NS}}$ & $0,47^{\mathrm{NS}}$ & $147.257,64^{\mathrm{NS}}$ & 81,27 \\
\hline LP 0657 & G10 & $1.359,10$ & 4,89 & $0,99^{\mathrm{NS}}$ & $47.715,11^{*}$ & 72,99 & $0,81^{\mathrm{NS}}$ & $1,60^{\mathrm{NS}}$ & $194.557,16^{*}$ & 81,16 \\
\hline LP 0658 & G11 & $1.269,60$ & 7,99 & $1,14^{\mathrm{NS}}$ & $88.115,80^{* *}$ & 69,32 & $0,96^{\mathrm{NS}}$ & $1,74^{*}$ & $358.577,68^{* *}$ & 75,03 \\
\hline LP 0659 & G12 & $1.546,00$ & 8,66 & $1,56^{* *}$ & $41.256,79 *$ & 88,06 & $1,72 * *$ & $1,02^{\mathrm{NS}}$ & $185.873,52 *$ & 91,23 \\
\hline LP 0660 & G13 & $1.493,50$ & 2,34 & $1,31^{\mathrm{NS}}$ & $-6.896,18^{\mathrm{NS}}$ & 95,59 & $1,42 *$ & 0,93 NS & $27.659,25^{\mathrm{NS}}$ & 97,98 \\
\hline LP 0661 & G14 & $1.495,20$ & 2,09 & $0,86^{\mathrm{NS}}$ & $4.246,27^{\mathrm{NS}}$ & 84,51 & $0,69^{\mathrm{NS}}$ & $1,45^{\mathrm{NS}}$ & $26.246,48^{\mathrm{NS}}$ & 96,13 \\
\hline LP 0662 & G15 & $1.534,30$ & 4,07 & $0,93^{\mathrm{NS}}$ & $34.879,34^{*}$ & 74,28 & $1,08^{\mathrm{NS}}$ & $0,41^{\mathrm{NS}}$ & $168.363,50^{\mathrm{NS}}$ & 80,97 \\
\hline LP 0663 & G16 & $1.330,60$ & 4,27 & $1,33^{*}$ & $17.969,57^{\mathrm{NS}}$ & 89,45 & $1,25^{\mathrm{NS}}$ & $1,59^{\mathrm{NS}}$ & $144.605,64^{\mathrm{NS}}$ & 90,46 \\
\hline LP 0664 & G17 & $1.398,50$ & 11,92 & $0,88^{\mathrm{NS}}$ & $145.302,70^{* *}$ & 47,22 & $0,70^{\mathrm{NS}}$ & $1,52^{\mathrm{NS}}$ & $577.675,50^{* *}$ & 54,45 \\
\hline LP 0665 & G18 & $1.610,40$ & 2,61 & $1,29^{\mathrm{NS}}$ & $-747,30^{\mathrm{NS}}$ & 93,73 & $1,35^{\mathrm{NS}}$ & $1,09^{\mathrm{NS}}$ & $76.226,45^{\mathrm{NS}}$ & 94,38 \\
\hline LP 0666 & G19 & $1.256,20$ & 8,84 & $0,47^{* *}$ & $50.992,56^{*}$ & 37,10 & $0,60^{*}$ & $0,04 * *$ & $249.032,63^{*}$ & 46,36 \\
\hline LP 0667 & G20 & $1.265,40$ & 2,18 & $0,82^{\mathrm{NS}}$ & $2.627,99^{\mathrm{NS}}$ & 83,85 & $0,86^{\mathrm{NS}}$ & $0,67^{\mathrm{NS}}$ & $93.618,07^{\mathrm{NS}}$ & 84,66 \\
\hline Média & & $1.445,10$ & & & & & & & & \\
\hline
\end{tabular}

NS não significativo; ** significativo a $1 \%$ probabilidade; * significativo a $5 \%$ probabilidade.

O método de Wricke (1965), como salientado anteriormente, indica os genótipos que mais contribuíram para a interação GxA, porém não consegue mostrar o desempenho dos genótipos, exigindo a complementação por outras metodologias de análise de adaptabilidade.

Entre as metodologias disponíveis, o método de Eberhart e Russell (1966) consegue detalhar o comportamento dos genótipos, visto que estima a adaptabilidade, estabilidade e também o coeficiente de previsibilidade de cada genótipo. Este modelo utiliza a regressão da média de cada genótipo em cada ambiente em relação a um índice ambiental sendo que, a inclinação da reta indica a adaptabilidade do genótipo. Quando $\beta 1$ for maior que 1 o genótipo é mais adaptado a ambientes favoráveis e $\beta 1$ menor que 1 o genótipo é adaptado a ambientes desfavoráveis. Os genótipos que obtiverem $\beta 1$ igual a 1 apresentam adaptabilidade ampla aos ambientes.

Antes de se observar a inclinação da reta de regressão, é necessário verificar a posição desta reta, ou seja, a média geral do genótipo. Este método também apresenta o coeficiente de determinação da regressão e estes valores indicam a previsibilidade $\left(\mathrm{R}^{2}\right)$ dos genótipos nos ambientes: quanto maior o valor de $\mathrm{R}^{2}$, mais previsível é o genótipo. Os desvios em torno da reta indicam a estabilidade. Portanto, quanto mais próximo o ponto da reta, ou seja, menor o desvio, maior o $\mathrm{R}^{2}$, mais previsível é o genótipo. Na análise de Eberhart e Russell (1966) 
sugere-se enfocar prioritariamente a posição da reta no gráfico, ou seja a média de produtividade e posteriormente a inclinação dessa reta $(\beta 1)$.

Na análise proposta por Eberhart e Russell(1966), para o grupo carioca 1 (Tabela 3 ), o genótipo que mais se destacou foi G17 pela alta produtividade média de grãos, adaptabilidade aos ambientes favoráveis, com $\beta 1$ igual a 2,49 , porém com baixa estabilidade ( $\mathrm{s}^{2} \mathrm{~d}>$ zero) e $\mathrm{R}^{2}$ igual a $86,24 \%$. O genótipo G13 apresentou produtividade de grãos média superior às três testemunhas, adaptabilidade a ambientes favoráveis $(\beta 1=1,55)$, boa estabilidade $\left(s^{2} \mathrm{~d}=\right.$ zero $)$ e alta previsibilidade $\left(\mathrm{R}^{2}=91,75 \%\right)$. Os genótipos de ampla adaptabilidade não apresentaram as melhores médias.

$\mathrm{Na}$ avaliação do grupo carioca 2 (Tabela 4), o genótipo G7 destacou-se por apresentar alta produtividade de grãos média, adaptação a ambientes favoráveis $(\beta 1=1,31)$, alta estabilidade $\left(s^{2} d=\right.$ zero $)$ e alta previsibilidade $\left(\mathrm{R}^{2}=99,88\right)$. A testemunha IPR Juriti (G2) e o genótipo G20 apresentaram ampla adaptabilidade, alta estabilidade e previsibilidade.

Para o grupo comercial carioca 3 (Tabela 5), pelo método de Eberhart e Russell, o genótipo G18 destacou-se por apresentar produtividade de grãos média elevada e ampla adaptabilidade, porém com baixa estabilidade e previsibilidade de comportamento. Os genótipos G1 e G4 apresentaram ampla adaptabilidade e alta estabilidade e previsibilidade de comportamento. Os genótipos G14 e G15 mostraram-se adaptados a ambientes desfavoráveis com alta estabilidade e previsibilidade. A cultivar IPR Saracura (G3) foi a mais produtiva, com adaptação ampla, porém com baixa estabilidade e previsibilidade.

No grupo comercial preto 1 (Tabela 6), os genótipos G5, G7 e G18 apresentaram média de produtividade de grãos média elevada. Os genótipos G5 e G18 apresentaram adaptação ampla e alta estabilidade e previsibilidade; o G7 destacou-se por possuir adaptabilidade a ambientes favoráveis, alta estabilidade e previsibilidade.

$\mathrm{Na}$ (Tabela 7) (preto 2), os genótipos G8, G9 e G16 apresentaram produtividade de grãos média elevada, adaptação ampla, porém apenas o G9 apresentou alta estabilidade e previsibilidade de comportamento. 
Tabela 7. Análise de adaptabilidade e estabilidade de 20 genótipos/cultivares de feijão Preto 2, avaliados em 6 ambientes do estado do Paraná (Londrina, Irati, Ponta Grossa e Pato Branco), nos anos agrícolas 2006 (feijão das águas) e 2007 (feijão das seca).

\begin{tabular}{|c|c|c|c|c|c|c|c|c|c|c|}
\hline \multirow{2}{*}{$\begin{array}{c}\text { Cultivar/ } \\
\text { Linhagem }\end{array}$} & \multirow[b]{2}{*}{$\mathrm{N}^{\circ}$} & \multirow{2}{*}{$\begin{array}{l}\text { Média } \\
(\mathrm{kg} / \mathrm{ha})\end{array}$} & \multirow{2}{*}{$\begin{array}{l}\text { Wricke } \\
\text { Wi (\%) }\end{array}$} & \multicolumn{3}{|c|}{ Eberhart e Russel } & \multicolumn{4}{|c|}{ Cruz, Torres e Vencovsky } \\
\hline & & & & $\beta 1$ & $\mathrm{~s}^{2} \mathrm{~d}$ & $\mathrm{R}^{2}(\%)$ & $\beta 1$ & $\beta 1+\beta 2$ & QM Desvio & $\mathrm{R}^{2}(\%)$ \\
\hline $\begin{array}{l}\text { IPR } \\
\text { UIRAPURU }\end{array}$ & G1 & $1.642,90$ & 2,71 & $1,15^{\mathrm{NS}}$ & $22.459,85^{* *}$ & 92,17 & $1,13^{\mathrm{NS}}$ & $1,82^{*}$ & $99.893,70^{* *}$ & 93,42 \\
\hline $\begin{array}{l}\text { IPR } \\
\text { CHOPIM }\end{array}$ & $\mathrm{G} 2$ & $1.312,90$ & 5,19 & $0,66^{* *}$ & $32.014,70^{* *}$ & 74,73 & $0,67 * *$ & $0,59^{\mathrm{NS}}$ & $156.840,36^{* *}$ & 74,77 \\
\hline $\begin{array}{l}\text { IPR } \\
\text { GRAUNA }\end{array}$ & G3 & $1.474,80$ & 4,15 & $1,04^{\mathrm{NS}}$ & $47.184,30^{* *}$ & 83,97 & $1,02^{\mathrm{NS}}$ & $1,48^{\mathrm{NS}}$ & $209.685,56^{* *}$ & 84,56 \\
\hline LP 0668 & G4 & $1.374,90$ & 1,66 & $0,84^{*}$ & $7.845,69^{\mathrm{NS}}$ & 92,42 & $0,86^{\mathrm{NS}}$ & $0,37^{\mathrm{NS}}$ & $51.128,89^{\mathrm{NS}}$ & 93,59 \\
\hline LP 0669 & G5 & $1.155,30$ & 12,92 & $0,41 * *$ & $73.085,59^{* *}$ & 35,72 & $0,48 * *$ & $-1,19 * *$ & $213.304,52^{* *}$ & 57,33 \\
\hline LP 0670 & G6 & $1.535,40$ & 6,99 & $1,21^{*}$ & $73.891,77^{* *}$ & 82,53 & $1,12^{\mathrm{NS}}$ & $3,42 * *$ & $118.119,56^{* *}$ & 93,64 \\
\hline LP 0671 & G7 & $1.697,70$ & 3,92 & $0,93^{\mathrm{NS}}$ & $43.307,65^{* *}$ & 81,74 & $0,89^{\mathrm{NS}}$ & $1,99^{*}$ & $154.985,39^{* *}$ & 86,00 \\
\hline LP 0672 & G8 & $1.705,10$ & 2,30 & $1,09^{\mathrm{NS}}$ & $20.867,86^{* *}$ & 91,80 & $1,12^{\mathrm{NS}}$ & $0,45^{\mathrm{NS}}$ & $95.040,10^{* *}$ & 93,07 \\
\hline LP 0673 & G9 & $1.750,90$ & 0,65 & $1,12^{\mathrm{NS}}$ & $-2.338,70^{\mathrm{NS}}$ & 98,53 & $1,12^{\mathrm{NS}}$ & $1,14^{\mathrm{NS}}$ & $19.649,88^{\mathrm{NS}}$ & 98,53 \\
\hline LP 0674 & G10 & $1.547,60$ & 5,16 & $1,24 * *$ & $46.502,75^{* *}$ & 88,18 & $1,24 * *$ & $1,21^{\mathrm{NS}}$ & $215.014,14^{* *}$ & 88,18 \\
\hline LP 0675 & G11 & $1.490,20$ & 4,33 & $1,00^{\mathrm{NS}}$ & $50.098,80^{* *}$ & 82,18 & $0,96^{\mathrm{NS}}$ & $2,11^{* *}$ & $177.627,30^{* *}$ & 86,20 \\
\hline LP 0676 & G12 & $1.665,60$ & 6,47 & $1,45^{* *}$ & $25.284,97^{* *}$ & 94,43 & $1,46^{* *}$ & $1,22^{\mathrm{NS}}$ & $127.999,92^{* *}$ & 94,53 \\
\hline LP 0677 & G13 & $1.589,10$ & 4,68 & $1,01^{\mathrm{NS}}$ & $54.656,53 * *$ & 81,33 & $1,01^{\mathrm{NS}}$ & $1,14^{\mathrm{NS}}$ & $246.937,09^{* *}$ & 81,39 \\
\hline LP 0678 & G14 & $1.635,00$ & 2,46 & $0,96^{\mathrm{NS}}$ & $24.856,94^{* *}$ & 88,27 & $0,97^{\mathrm{NS}}$ & $0,61^{\mathrm{NS}}$ & $123.363,27^{* *}$ & 88,74 \\
\hline LP 0679 & G15 & $1.665,90$ & 3,00 & $1,10^{\mathrm{NS}}$ & $29.722,32 * *$ & 89,62 & $1,07^{\mathrm{NS}}$ & $1,82 *$ & $125.923,14^{* *}$ & 91,16 \\
\hline LP 0680 & G16 & $1.869,70$ & 10,97 & $0,98^{\mathrm{NS}}$ & $137.936,35^{* *}$ & 63,23 & $1,04^{\mathrm{NS}}$ & $-0,67 * *$ & $466.414,94^{* *}$ & 70,47 \\
\hline LP 0681 & G17 & $1.647,50$ & 7,69 & $1,30 * *$ & $71.775,16^{* *}$ & 84,79 & $1,30 * *$ & $1,13^{\mathrm{NS}}$ & $314.989,85^{* *}$ & 84,85 \\
\hline LP 0682 & G18 & $1.539,20$ & 4,35 & $0,85^{\mathrm{NS}}$ & $44.173,69^{* *}$ & 78,56 & $0,89^{\mathrm{NS}}$ & $-0,28^{* *}$ & $151.900,80^{* *}$ & 84,17 \\
\hline LP 0683 & G19 & $1.326,50$ & 7,41 & $0,81^{*}$ & $81.236,29 * *$ & 65,97 & $0,83^{*}$ & $0,32^{\mathrm{NS}}$ & $343.819,48^{* *}$ & 66,95 \\
\hline LP 0684 & G20 & $1.561,80$ & 2,98 & $0,85^{\mathrm{NS}}$ & $26.305,31^{* *}$ & 84,95 & $0,83^{*}$ & $1,31^{\mathrm{NS}}$ & $125.468,73^{* *}$ & 85,94 \\
\hline Média & & $1.559,4$ & & & & & & & & \\
\hline
\end{tabular}

NS não significativo; $* *$ significativo a $1 \%$ probabilidade; $*$ significativo a $5 \%$ probabilidade.

O método proposto por Cruz et al., (1989) contém dois seguimentos de reta, a qual é dada por $\beta 1$, para os ambientes desfavoráveis e $\beta 1+\beta 2$ para os ambientes favoráveis. Neste caso, é desejável que o genótipo mais adaptado tenha valor de $\beta 1$ menor do que $1, \beta 1+\beta 2$ maior do que 1 , indicando que nos ambientes favoráveis a média do genótipo aumenta a taxas maiores do que o aumento da média ambiental, e desvios de regressão igual a zero $\left(\mathrm{s}^{2} \mathrm{~d}\right.$ $=$ zero).

Utilizando-se o método de Cruz et al. (1989), na avaliação dos cinco grupos estudados: carioca 1, 2 e 3 e preto 1 e 2 (Tabelas 3 a 7), não foi encontrado nenhum genótipo preconizado como ideal, ou seja, com produtividade de grãos média elevava, $\beta 1<1$, $\beta 1+\beta 2>1$ e s ${ }^{2} \mathrm{~d}=$ zero. A metodologia de Cruz et al. (1989) sofre limitações quando se dispõe de poucos ambientes para estudo, como é o presente caso, visto que, por dividir os dados em duas regiões em ambientes desfavoráveis e favoráveis, reduz ainda mais a disponibilidade de pontos, enfraquecendo a análise.

Outro método que está sendo bastante utilizado para verificar a estabilidade e adaptabilidade de genótipos é o método de análise AMMI, que significa modelo de efeitos aditivos principais e interação multiplicativa. Por meio da análise de variância pelo método AMMI foram definidos os modelos AMMI 2, AMMI 1, AMMI 3, AMMI 3, AMMI 3 para os grupos carioca $1,2,3$ e preto 1,2 , respectivamente. 
As explicações acumuladas para os grupos de feijão foram as seguintes: $81 \%$ para carioca $1 ; 70 \%$ para carioca $2 ; 72 \%$ para carioca $3 ; 85 \%$ para preto 1 ; e $80 \%$ para preto 2 (Tabela 8 ). Entre esses os que menos retiveram "ruído" para a interação GxA foi carioca 1 , preto 1 e preto 2 , com apenas 15 a $20 \%$ de erro, indicando que o experimento foi conduzido de forma adequada.

Tabela 8. Decomposição da $\mathrm{SQ}_{\mathrm{GxA}}$ e porcentagem de explicação de cada componente principal, da análise de estabilidade e adaptabilidade do método AMMI, dos grupos de feijão (carioca 1, 2, 3 e preto 1 e 2), nos locais do Paraná, nas épocas de semeadura das águas (2006) e das seca (2007).

\begin{tabular}{|c|c|c|c|c|c|c|c|c|c|c|}
\hline \multirow[b]{2}{*}{$\mathrm{CP}^{(1)}$} & \multicolumn{2}{|c|}{ Carioca 1} & \multicolumn{2}{|c|}{ Carioca 2} & \multicolumn{2}{|c|}{ Carioca 3} & \multicolumn{2}{|c|}{ Preto 1} & \multicolumn{2}{|c|}{ Preto 2} \\
\hline & $\%$ Expl. $^{(2)}$ & $\begin{array}{c}\text { \% Expl. } \\
\text { Ac. }{ }^{(3)}\end{array}$ & \% Expl. & $\begin{array}{c}\text { \% Expl. } \\
\text { Ac. }\end{array}$ & $\begin{array}{c}\% \\
\text { Expl. }\end{array}$ & $\begin{array}{c}\text { \% Expl. } \\
\text { Ac. }\end{array}$ & \% Expl. & $\begin{array}{c}\text { \% Expl. } \\
\text { Ac. }\end{array}$ & $\begin{array}{c}\% \\
\text { Expl. }\end{array}$ & $\begin{array}{c}\% \text { Expl. } \\
\text { Ac. }\end{array}$ \\
\hline 1 & 55,70 & 55,76 & 70,40 & 70,42 & 55,10 & 55,10 & 41,03 & 41,03 & 32,93 & 32,93 \\
\hline 2 & 25,28 & 81,04 & 20,10 & 90,53 & 17,24 & 72,34 & 25,29 & 66,32 & 29,40 & 62,33 \\
\hline 3 & 14,29 & 95,33 & 9,50 & 100,00 & 13,33 & 85,67 & 19,13 & 85,45 & 18,00 & 80,33 \\
\hline 4 & 4,66 & 100,00 & - & - & 8,93 & 94,60 & 9,45 & 94,89 & 14,41 & 94,74 \\
\hline 5 & - & - & - & - & 5,40 & 100,00 & 5,11 & 100,00 & 5,26 & 100,00 \\
\hline
\end{tabular}

$\mathrm{CP}=$ Componente Principal; \% Expl.= Porcentagem explicada da soma de quadrados da interação; \% Expl.Ac.= Porcentagem da explicação acumulada da soma de quadrados da interação; (-): não há dados

Para facilitar a interpretação deste método foram construídos os biplots, que são gráficos compostos por pontos, representando os genótipos e os ambientes (Figura 1). Nestes gráficos optouse por demonstrar o comportamento dos genótipos mediante a produtividade de grãos média nas abscissas e o componente principal 1 (IPCA1) no eixo das ordenadas, independentemente do modelo AMMI indicado pela análise de variância, na qual o primeiro componente (IPCA 1) foi o componente que explicou mais a variação observada em todos os grupos de feijão analisados (Tabela 9).

Tabela 9. Análise de variância conjunta da análise de estabilidade e adaptabilidade do método AMMI, dos grupos de feijão (carioca 1, 2, 3 e preto 1 e 2), nos locais do Paraná, nas épocas de semeadura das águas (2006) e das seca (2007).

\begin{tabular}{|c|c|c|c|c|c|c|c|c|c|c|}
\hline \multirow[b]{2}{*}{$\mathrm{FV}$} & \multicolumn{2}{|c|}{ CARIOCA 1} & \multicolumn{2}{|c|}{ CARIOCA 2} & \multicolumn{2}{|c|}{ CARIOCA 3} & \multicolumn{2}{|c|}{ PRETO 1} & \multicolumn{2}{|c|}{ PRETO 2} \\
\hline & GL & QM & GL & QM & GL & QM & GL & QM & GL & QM \\
\hline Genótipos (G) & 19 & $* *$ & 19 & $* *$ & 19 & $* *$ & 19 & $* *$ & 19 & $* *$ \\
\hline Ambientes (A) & 4 & $* *$ & 3 & $* *$ & 5 & $* *$ & 5 & $* *$ & 5 & $* *$ \\
\hline GxA & 76 & $* *$ & 57 & $* *$ & 95 & $* *$ & 95 & $* *$ & 95 & $* *$ \\
\hline CP 1 & 22 & $* *$ & 21 & $* *$ & 23 & $* *$ & 23 & $*$ & 23 & $* *$ \\
\hline $\mathrm{CP} 2$ & 20 & NS & 19 & $* *$ & 21 & $* *$ & 21 & NS & 21 & $* *$ \\
\hline $\mathrm{CP} 3$ & 18 & NS & 17 & NS & 19 & $*$ & 19 & NS & 19 & $*$ \\
\hline Desvios & 16 & NS & 0 & NS & 32 & NS & 32 & NS & 32 & $*$ \\
\hline Resíduo & 190 & - & 152 & - & 228 & - & 228 & - & 228 & - \\
\hline
\end{tabular}

NS: não significativo; ** significativo a $1 \%$ probabilidade; * significativo a $5 \%$ probabilidade

(-): não há dados. 
Nestes gráficos, o genótipo ideal deve estar o mais a direita possível no eixo $\mathrm{X}$, ou seja, com maior produtividade de grãos média e apresentar valores de IPCA1 (eixo Y) próximos ao ponto zero, pois se trata de um genótipo estável. Quanto maior for a distância dos genótipos da origem do eixo AMMI da interação (AMMI) maior será a contribuição para a interação GxA. Na (Figura 1) (carioca 1), o genótipo G17 contribuiu com a interação GxA e, portanto, possivelmente pode-se tratar do genótipo mais produtivo e que apresentou os maiores desvios. Pacheco et al. (2005) afirmaram, que pelo método de AMMI, a seleção de genótipos com alta estabilidade, geralmente, resulta em baixas produtividades de grãos e, reciprocamente, a seleção para produtividades de grãos mais altas pode conduzir à menor estabilidade. Os genótipos mais estáveis estão mais próximos ao ponto de origem, e dentre eles estão: G3, G9, G12 e G13. Para a análise de adaptabilidade, os genótipos devem estar o mais próximo dos referidos ambientes. Portanto, o genótipo G18 está adaptado ao ambiente Pato Branco - seca (A5); G11, G12 e G13 ao ambiente Irati - seca (A3); e G2 e G16 ao ambiente Irati águas (A2).
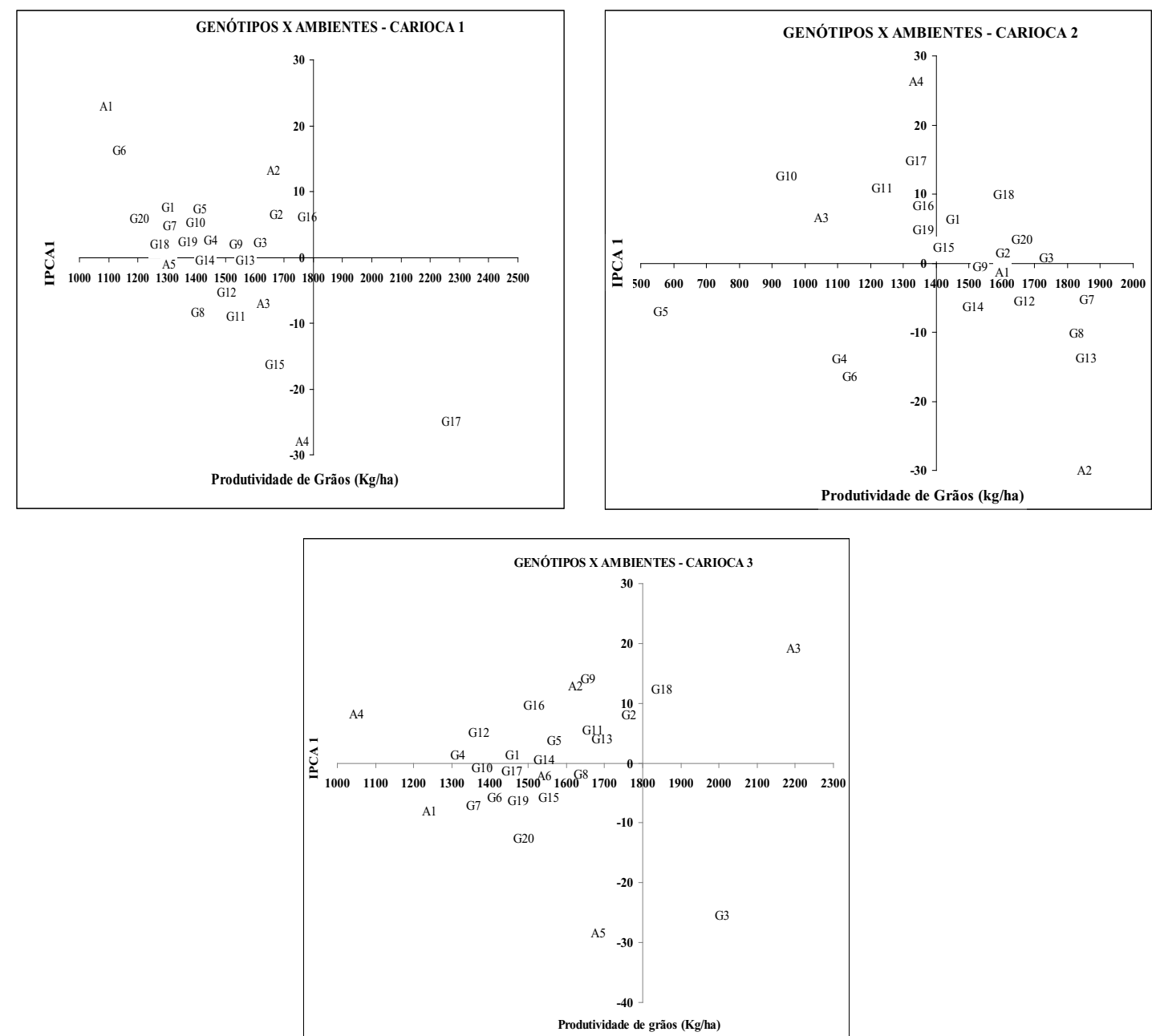

Figura 1. Biplots da análise AMMI, considerando o primeiro componente principal em relação à média de produtividade de grãos ( $\mathrm{kg} / \mathrm{ha}$ ), para a estabilidade e adaptabilidade de 20 genótipos/cultivares dos grupos de feijão carioca 1, carioca 2, carioca 3, avaliados nos ambientes do estado do Paraná (Londrina, Irati, Ponta Grossa e Pato Branco), nos anos agrícolas 2006 (feijão das águas) e 2007 (feijão das seca). 
$\mathrm{Na}$ análise dos ambientes (Figura 1, Carioca 1), o ambiente A5 (Pato Branco - seca) foi o que contribuiu menos com a interação, com média de produção de $1.250 \mathrm{~kg} / \mathrm{ha}$, e este porém, não atingiu a média geral dos ambientes $(1.450 \mathrm{~kg} / \mathrm{ha})$. Entretanto, esse ambiente é classificado como desfavorável, devido a sua baixa produtividade de grãos. Segundo Oliveira et al. (2003), a estabilidade ambiental pela análise AMMI informa a confiabilidade no ordenamento dos genótipos em um dado ambiente de teste, em relação à classificação para a média dos ambientes testados.

Na Figura 1 (Carioca 2), os genótipos G3, G7, G8 e G13 no biplot apresentaram-se como os mais produtivos. O ambiente Ponta Grossa - seca (A2) apresentou a maior produtividade de grãos média e, em conseqüência, esse ambiente foi altamente influenciado pela interação GxA, como também os ambientes Pato Branco - seca (A3) e Londrina águas (A4). Por outro lado, o ambiente Irati - seca (A1) foi o mais estável e os genótipos G14 e G9 foram os mais estáveis dentro desse ambiente.
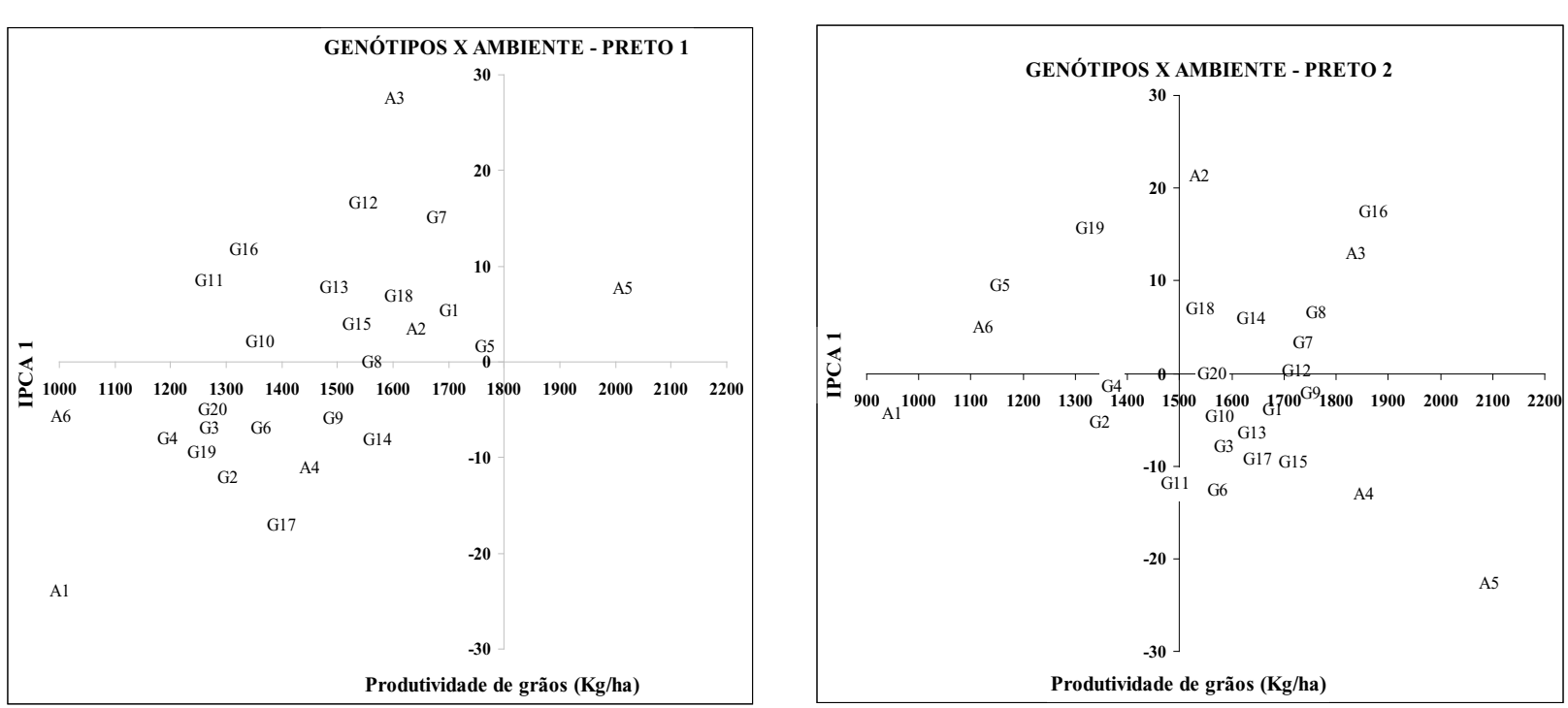

Figura 2. Biplots da análise AMMI, considerando o primeiro componente principal em relação à média de produtividade de grãos (kg/ha), para a estabilidade e adaptabilidade de 20 genótipos/cultivares dos grupos de feijão preto 1 e preto 2 , avaliados nos ambientes do estado do Paraná (Londrina, Irati, Ponta Grossa e Pato Branco), nos anos agrícolas 2006 (feijão das águas) e 2007 (feijão das seca).
No grupo do feijão carioca 3 (Figura 1), vários genótipos estão localizados próximos ao ponto de origem e os mais estáveis são G1 e G17. O genótipo G3 e G18, os quais apresentaram produtividade de grãos média elevada, são considerados os mais instáveis. Os ambientes Pato Branco - seca (A4) e Londrina - águas (A1) contribuíram menos com a interação GxA e produziram muito abaixo do esperado, e por isso eles estão classificados como ambientes desfavoráveis. O ambiente Irati - seca (A6) foi o mais estável, sendo que nesse ambiente destacaram-se para estabilidade os genótipos G14, G15 e G19.

$\mathrm{Na}$ (Figura 2) (preto 1), os genótipos que estão próximos ao ponto zero, são estáveis principalmente, G8, G9, G13, G14 e G15. O ambiente Irati águas (A2) foi o mais estável, destacando-se para estabilidade nesse ambiente os genótipos G1, G8, G15 e G18. O ambiente que mais contribuiu para a interação GxA foi Ponta Grossa - seca (A5), o qual apresentou média de produtividade de grãos acima de $2.000 \mathrm{~kg} / \mathrm{ha}$ e foi classificado como ambiente favorável. 
Analisando-se o grupo de feijão preto 2 (Figura 2), observa-se que os genótipos G2, G3, G4, G10 e G20 foram os mais estáveis e G16 o menos estável. Nesse grupo nenhum ambiente apresentou estabilidade. Os ambientes, Irati - seca (A4), Ponta Grossa - seca (A5) e Pato Branco - águas (A3) foram os ambientes mais responsivos em termo de produtividade de grãos.

Estudos realizados com feijão-caupi (Vigna unguiculata), utilizando-se o método AMMI para a análise da adaptabilidade, estabilidade e da interação genótipo x ambiente, mostraram que a metodologia utilizada forneceu informações mais detalhadas para os parâmetros analisados (FREIRE FILHO et al., 2003, 2005).
Uma comparação entre as quatro metodologias utilizadas para o estudo da estabilidade e adaptabilidade dos genótipos é apresentada na (Tabela 10). Essa comparação foi efetuada por meio de correlações simples de Pearson entre os parâmetros de adaptabilidade e estabilidade obtidos em cada método. As correlações significativas obtidas pelo teste $\mathrm{t}$ ao nível de $1 \%$ e $5 \%$ de probabilidade indicam a consistência entre os diferentes métodos de estabilidade e adaptabilidade fenotípica estudados. Essa consistência baseou-se na freqüência de mesma resposta entre os cinco grupos de ensaios testados e que estão representados em porcentagem (\%).

Tabela 10. Correlações em porcentagem mais consistentes entre os diferentes parâmetros de quatro metodologias de análise de estabilidade fenotípica, a saber, Wricke (Wi\%), Eberhart \& Russell (EB), Cruz et al., para os cincos grupos de ensaios de feijão no estado do Paraná.

\begin{tabular}{|c|c|c|c|c|c|}
\hline \multicolumn{6}{|c|}{ ESTABILIDADE } \\
\hline \multirow[b]{2}{*}{ Correlação\% } & \multirow[b]{2}{*}{ Wi } & \multirow[b]{2}{*}{$\mathrm{s}^{2} \mathrm{~d}(\mathrm{~EB})$} & \multirow[b]{2}{*}{ QM desvio (Cruz) } & \multicolumn{2}{|c|}{ AMMI } \\
\hline & & & & Escore 1 & Escore 2 \\
\hline \multirow[t]{2}{*}{ Wi } & - & +80 & +80 & 0 & 0 \\
\hline & - & 0 & 0 & -40 & 0 \\
\hline \multirow[t]{2}{*}{$\mathrm{s}^{2} \mathrm{~d}^{(1)}(\mathrm{EB})$} & - & - & +80 & 0 & +20 \\
\hline & - & - & 0 & -20 & - \\
\hline \multirow[t]{2}{*}{ QM desvio (Cruz) ${ }^{(2)}$} & - & - & - & +20 & +20 \\
\hline & - & - & - & -20 & 0 \\
\hline \multirow[t]{2}{*}{ Escore 1 (AMMI) } & - & - & - & - & 0 \\
\hline & - & - & - & - & - \\
\hline \multirow[t]{2}{*}{ Escore2 (AMMI) } & - & - & - & - & - \\
\hline & \multicolumn{3}{|c|}{ ADAPTABILIDADE } & & \\
\hline \multicolumn{6}{|c|}{ AMMI } \\
\hline \multirow{3}{*}{$\begin{array}{l}\text { Correlação \% } \\
\text { Média }\end{array}$} & $\mathrm{B} 1(\mathrm{~EB})$ & $\beta 1$ (Cruz) & $\beta 1+\beta 2($ Cruz $)$ & Escore 1 & Escore 2 \\
\hline & +80 & +80 & +20 & +20 & 0 \\
\hline & 0 & 0 & -20 & -20 & -20 \\
\hline \multirow[t]{2}{*}{$\beta 1(\mathrm{~EB})^{(3)}$} & - & +80 & +80 & +20 & +40 \\
\hline & - & 0 & -20 & -40 & -40 \\
\hline \multirow[t]{2}{*}{$\beta 1(\mathrm{Cruz}){ }^{(4)}$} & - & - & +60 & 0 & +60 \\
\hline & - & - & 0 & 0 & -20 \\
\hline \multirow[t]{2}{*}{$\beta 1+\beta 2(\mathrm{Cruz})^{(5)}$} & - & - & - & 0 & +20 \\
\hline & - & - & - & -60 & -40 \\
\hline \multirow[t]{2}{*}{ Escore1 (AMMI) } & - & - & - & - & 0 \\
\hline & - & - & - & - & - \\
\hline Escore 2 (AMMI) & & - & - & - & - \\
\hline
\end{tabular}

$\mathrm{s}^{2} \mathrm{~d}=$ estabilidade (Eberhart \& Russell); QM desvio= estabilidade de Cruz; $\beta 1(\mathrm{~EB})=$ adaptabilidade $($ Eberhart \& Russell); $\beta 1(\mathrm{Cruz})=$ adaptabilidade ambiente desfavorável (Cruz); $\beta 1+\beta 2$ (Cruz)= adaptabilidade ambiente favorável (Cruz); (-): não há dados. 
Para estabilidade, o método Wricke correlacionou-se positivamente com $\mathrm{s}^{2} \mathrm{~d}$ (EB), QM desvio (CRUZ et al., 1989) em 80\% dos grupos, mas não obteve correlação com o método AMMI. A estabilidade ( $\mathrm{s}^{2} \mathrm{~d}$ ) pelo método Eberhart e Russell também foi correlacionada positivamente com o QM desvio de Cruz na freqüência de $80 \%$ dos grupos.

Quanto à adaptabilidade, houve correlação positiva entre os métodos de $\mathrm{EB}(\beta 1)$ com Cruz ( $\beta 1 \mathrm{e}$ $\beta 1+\beta 2$ ) em $80 \%$ dos grupos e $40 \%$ de correlação positiva entre o método EB ( $\beta 1$ ) e AMMI (escore 2).

Para a média de produtividade de grãos, obteve-se correlação positiva e significativa entre o parâmetro de adaptabilidade $\beta 1$ pelo método de EB e Cruz em $80 \%$ dos grupos em ambos os métodos e em $20 \%$ dos grupos houve correlação da média com AMMI (escore 1).

A adaptabilidade em ambientes desfavoráveis $(\beta 1)$ e favoráveis $(\beta 1+\beta 2)$ de Cruz e também para o método AMMI (escore 2) apresentou correlação positiva em $60 \%$ dos grupos. Para ambientes favoráveis $(\beta 1+\beta 2)$ no método Cruz houve correlação negativa entre AMMI (escore 1) em 60\% dos grupos. Os demais parâmetros entre os métodos obtiveram correlação mínima e também não houve correlação significativa.

As estimativas dos coeficientes de correlação entre os métodos de Eberhart e Russel e AMMI encontrados por Mello et al. (2007) e Silva e Duarte (2006) indicaram baixa correlação entre esses dois métodos, os quais estão de acordo com os resultados obtidos no presente trabalho.

Prado et al. (2001) utilizaram os métodos de ecovalência, Cruz et al. (1989) e Eberhart e Russell (1966) na avaliação de cultivares de soja. Estes autores concluíram que os métodos utilizados foram coerentes entre si, permitindo a identificação das cultivares com maior estabilidade e adaptabilidade. Observaram também o comportamento produtivo das cultivares de soja ao longo das épocas de semeadura e que foi bem representado pelo modelo linear proposto Eberhart e Russell (1966).

\section{Conclusões}

Entre os grupos de feijoeiro, considerando a previsibilidade, estabilidade e adaptabilidade aos ambientes favoráveis e a produtividade de grãos média, entre os métodos estudados, os genótipos que mais se enquadram nestes aspectos são: LP 0622 (G13) (carioca 1), LP 0604 (G7) (carioca $2)$, nenhum genótipo se enquadrou nestes aspectos (carioca 3), LP 0652 (G5), LP 0654 (G7) e LP 06 65 (G18) (preto 1) e LP $0673 \mathrm{G} 9$ (preto2).

O ambiente Ponta Grossa - seca é o ambiente que mais contribuiu com a interação GxA e esse ambiente está classificado para ambientes favoráveis para todos os grupos comerciais de feijão.

$\mathrm{Na}$ análise de comparação entre os métodos, o método de Eberhart e Russel e Cruz et al. obtiveram correlação positiva e significativa em $80 \%$ dos grupos avaliados para a estabilidade e adaptabilidade dos genótipos.

\section{Referências}

CONAB. Safras. Acompanhamento da safra brasileira de grãos: nono levantamento, junho/2007. Brasília: Companhia Nacional de Abastecimento, 2007. 25p. (Quadro de oferta e demanda do feijão). Disponível em: <http://www.conab.gov.br/conabweb/download/ safra/9levsafra.pdf>. Acesso em: 21 jun. 2007.

CRUZ, C. D. Programa genes: aplicativo computacional em genética e estatística. Viçosa: UFV, 2001. 442p.

CRUZ, C. D.; CARNEIRO, P. C. S. Modelos biométricos aplicados ao melhoramento genético. Viçosa: Universidade Federal de Viçosa, 2003. v. 2.

CRUZ, C. D.; REGAZZI, A. J. Modelos biométricos aplicados ao melhoramento genético. Viçosa: UFV, 1997.

CRUZ, C. D.; TORRES, R. A.; VENCOVSKY, R. An alternative to the stability analysis proposed by Silva and Barreto. Revista Brasileira de Genética, Ribeirão Preto, v. 12, n. 2, p. 567-580, 1989.

EBERHART, S.A.; RUSSELL, W. A. Stability parameters for comparing varieties. Crop Science, Madison, v. 6, n. 1, p. 36- 40, 1966. 
FREIRE-FILHO, F. R.; RIBEIRO, V. Q.; ROCHA, M. M.; LOPES, A. C. A. Adaptabilidade e estabilidade da produtividade de grãos de genótipos de caupi enramador de tegumento mulato. Pesquisa Agropecuária Brasileira, Brasília, v. 38, n. 5, p. 591-598, 2003.

FREIRE FILHO, F. R.; ROCHA, M. M.; RIBEIRO, V. Q.; LOPES, A. C. A. Adaptabilidade e estabilidade produtiva de genótipos de feijão-caupi. Ciência Rural, Santa Maria, v. 35, n. 1, p. 24-30, 2005.

MELLO, L. C.; MELLO P. G. S.; FARIA, L. C.; DIAZ, J. L. C.; PELOSO, M. J. D.; RAVA, C. A.; COSTA, J. G. C. Interação com ambientes e estabilidade de genótipos de feijoeiro-comum na Região Centro- Sul do Brasil. Pesquisa Agropecuária Brasileira, Brasília , v. 42, n. 5, p. 715-723, 2007.

OLIVEIRA, A. B.; DUARTE, J. B.; PINHEIRO, J. B. Emprego da análise AMMI na avaliação da estabilidade produtiva em soja. Pesquisa Agropecuária Brasileira, Brasília, v. 38, n. 3, p. 357-364, 2003.
PACHECO, R. M.; DUARTE, J. B.; VENCOVSKY, R.; PINHEIRO, J. B.; OLIVEIRA, A. B. Use of supplementary genotypes in AMMI analysis. Theoretical And Applied Genetics, Stuttgart, Germany, v. 110, n. 5, p. 812-818, 2005.

PRADO, E. E.; HIROMOTO, D. M.; GODINHO, V. P. C.; UTUMI, M. M.; RAMALHO, A. R. Adaptabilidade e estabilidade de cultivares de soja em cinco épocas de plantio no cerrado de Rondônia. Pesquisa Agropecuária Brasileira, Brasília, v. 36, n. 4, p.625-635, 2001.

SILVA, W. C. J.; DUARTE, J. B. Métodos estatísticos para estudo de adaptabilidade e estabilidade fenotípica em soja. Pesquisa Agropecuária Brasileira, Brasília, v. 41, n. 1, p. 23-30, 2006.

WRICKE, G. Zur berechnung der okovalenz bei sommerweizen und hafer. Zeitschrift Pflanzenzuchtg, Berlin, v. 52, p.127-138, 1965.

ZOBEL, R. W.; WRIGHT, M. J.; GAUCH, H. G. Statistical analysis of a yield trial. Agronomy Journal, Madison, v. 80, n. 3, p. 388-393, 1988. 
